\title{
Prevalence of Acute Diarrhoea in Kathmandu Valley
}

\author{
Karki $A^{1}$, Tiwari $B R^{2}$ \\ 'Department of Microbiology, Nepalguni Medical College, Nepalgunj. \\ ${ }^{2}$ Blood Bank, Kathmandu, Nepal.
}

\section{ABSTRACT}

This retrospective study was conducted during January to September in the year 1997. Three hundred and forty nine stool samples were collected from diarrhoea patients from different places of Kathmandu valley and examined at National Public Health Laboratory (NPHL), Teku, Kathmandu. Acute diarrhoea becomes epidemic in rainy season and is a major public health problem of the city. In this study, people with poor hygiene practice and poor education were infected more than other people. Among the 349 patients with the gastrointestinal disease, $26.0 \%$ were found to have bacterial infection. Out of which, $88(25.1 \%)$, one $(0.28 \%)$, one $(0.28 \%)$, and one $(0.28 \%)$ were found to be Vibrio cholerae 01 , Vibrio cholerae 0139 , Shigella dysenteriae and Escherichia coli respectively. Cholera cases were found almost throughout the year in the city though the numbers increased during the rainy season. It was highest during July $(34.6 \%)$ followed by August (32.35\%), September 32\% and June (6.89\%). The uncommon species of Vibrio i.e. Vibrio cholerae 0139 was also found in the study. Higher prevalence was found in urban areas $(83.52 \%)$ than in rural areas $(16.48 \%)$. Antimicrobial susceptibility testing of bacterial isolates showed that Ciprofloxacin $(97.85 \%)$ was found to be the most effective antibiotic followed by Tetracycline (92.34\%), Erythromycin (92.34\%), Norfloxacin (93.34\%), Cholramphenicol, Ampicillim, but Cotrimoxazole were found to be resistant to all isolated Vibrio cholerae.

Key words: Diarrhoea, Prevalence, Shigella, Vibrio.

\section{INTRODUCTION}

Acute diarrhoea is a sudden alteration in normal bowel habits whereby normally formed stool passed daily changes to frequent, multiple loose to watery stools. ${ }^{1}$ Diarrhoea may be associated with increased frequency of defecation or increased liquidity of stools or both and often is an abnormal increase in daily stool weight (>200g/day). Diarrhoeal diseases are priority health problems in developing countries like Nepal. The diarrhoeal disease problem is complex and pervasive as it involves deep rooted cultural, behavioral and primary need factors. These are the most important health problems in the world today. Even with potentially lifesaving intervention of oral re-hydration therapy, the life prevalence of the organism and diarrhoea rates remain unchanged. The numbers of diarrhoeal cases and other intestinal infections have high morbidity and mortality rate in developing countries. It has been estimated that there are at least 500 million episodes of diarrhoea each year resulting directly or indirectly in five to ten million deaths in preschool children. According to World Health Organisation (WHO) analysis of 1998, four million children less than five years of age die annually in Asia, Africa and Latin America, $33 \%$ of deaths occurs under five years of age due to diarrhoea. Every year 30-40 thousands children die from the diarrhoeal disease. ${ }^{1}$ The case fatality rate (CFR) from acute diarrhea was found to be $1.95 \%$ in

\author{
Correspondence: \\ Aarati Karki \\ Department of Microbiology \\ Nepalguni Medical College \\ Nepalgunj, Nepal. \\ Email: aarati_karki@hotmail.com
}


$1991,0.13 \%$ in 1993 and $0.17 \%$ in 1994 . Acute diarrhoea may be caused by different viruses, bacteria like Salmonella spp, Shigella spp, Vibrio cholera and parasites. Among these pathogens, Vibrio cholerae is the most dangerous viral pathogen which has high fatality and mortality rate than other organisms. ${ }^{2}$

Epidemics of cholera are traditionally caused by Vibrio Cholerate '01' but this one was due to a new 01. Zero groups successfully named Vibrio cholerae 0139. This stream has also caused cholera like diseases in several neighboring countries of Asia. Vibrio cholerae have a more limited geographical distribution. However, such infection may be acquired by travelers to these areas and imported into their home countries. Cholera is a diarrhoeal disease, which affects only human. It has been regarded classically as a typically acute and often fatal infection. More recent epidemiological studies suggest that for every case of classical cholerae, these are 10-100 cases of mild or even inapparent infection. The causative agent of this disease is Vibrio cholera 01 and Vibrio cholerae 0139. Agents causing cholera 01 are usually ingested in contaminated water or food. ${ }^{2}$

Shigellosis also remains an important cause of diarrhoeal disease in Nepal. Its distribution is worldwide: two third of the cases, and most of the deaths in under ten years, occurs in countries with overcrowding and poor sanitation. ${ }^{3}$ Person to person spread is considered the main mode of Shigella transmission throughout the world. ${ }^{4}$ They are transmitted by direct and indirect faecooral route from a patient or carrier where a very small dose of organism is sufficient to cause the disease.

Vibrio cholera 01 causes a massive outpouring of fluid and electrolytes into the bowel. This rapidly leads to profuse watery, diarrhoeal loss of circulating blood volume, metabolic acidosis, potassium depletion and ultimately vascular collapse and death. In severe cases, pouring diarrohea can rapidly cause the loss of $10 \%$ or more of the body weight. Cholera is new and reemerging public health concerns in many parts of the world. The appearance of epidemic cholera in Latin America and the emergence in Asia of diseases caused by newly identified strain Vibrio cholerae 0139 indicate that cholerae will remain a challenge for years to come. Meeting this challenge with effective cholerae prevention and control measure will require application of reliable microbiological techniques. ${ }^{3}$

Although various works have been done and published on diarrhoeal disease in Nepal, epidemiological aspect of Vibrio cholerae in Kathmandu valley has not been published. Thus this study concentrates on isolation, identification, antibiotic profile, seasonal location, and other epidemiological parameters evaluating diarrhoeal epidemics in Kathmandu Valley in the year 1997.

\section{MATERIAL AND METHODS}

Three hundred and forty nine stool samples were collected from gastroenteritis patients from different places of Kathmandu valley and were examined at National Public health Laboratory (NPHL), Teku from January to September 1997 using standard methodology. ${ }^{5}$ The history of 349 patient including age, gender, symptoms, and duration of illness were studied. The laboratory diagnosis was done by macroscopic examination followed by standard culture methods using different culture media (APW, MA, TCBS and SS). Serotyping and antibiotic sensitivity test were performed for complete diagnosis of diarrhoeal pathogens using standard methodology. ${ }^{4}$

\section{RESULTS}

Stool samples of 349 patients suffering from diarrhoea were collected from January to September 1997, physical examination and culture of faeces were done. Among these, $25.5 \%$ were Vibrio cholerae 01, 0.28\% Vibrio cholerae 0139 and remaining other bacteria (Escherichia coli and Shigella dysenteriae) etc.

The table shows that number increased during the rainy season i.e. peak value seen in July 44 cases (34.6\%) followed by September (32\%), August (32.35\%) and June $(6.89 \%)$ (Table 1$)$.

The age and gender of all patients were recorded and are given on the table (Table 2 ) and educational status (Table 3).

Out of 349 diarrhoea patients, $54.94 \%$ were male and $45.05 \%$ were female. The group of $16-30$ years of age was found to be the most infected and the number of male patients was higher than the number of female patients (Figuer 1).

Educated are the ones who have graduation degree, Literate who can read and write, Illiterate who can not read and write. Lowest number of infections were found in the Educated group (9.89\%) while highest number was found among the Uneducated (57.14\%). (Table 4)

Lowest number of infections was found in people with good hygiene $(10.98 \%)$, and highest number was seen in people with poor hygiene $(67.03 \%)$.

Ninety one isolates were subjected for antibiotic sensitivity 
Karki et al. Prevalence of Acute Diarrhoea in Kathmandu Valley

Table 1. Monthly occurrence of diarrhoea pathogens from Jan. to Sept. 1997 in Kathmandu in NPHL.

\begin{tabular}{|c|c|c|c|c|c|c|c|c|c|c|c|}
\hline \multirow[t]{2}{*}{ Month } & \multicolumn{3}{|c|}{$\begin{array}{l}\text { Total cases of } \\
\text { gastroenteritis }\end{array}$} & \multicolumn{2}{|c|}{ Vibrio cholerae 01} & \multicolumn{2}{|c|}{$\begin{array}{c}\text { Vibrio cholerae } \\
0139\end{array}$} & \multicolumn{2}{|c|}{ Shigella dysenteriae } & \multicolumn{2}{|c|}{ Escherichia coli } \\
\hline & Male & Female & Total & Total & $\%$ & Total & $\%$ & Total & $\%$ & Total & $\%$ \\
\hline Jan & 1 & 2 & 3 & - & - & - & - & - & - & - & - \\
\hline Feb & 2 & - & 2 & - & - & - & - & - & - & - & - \\
\hline Mar & 4 & 6 & 10 & - & - & - & - & - & - & - & - \\
\hline Apr & 7 & 4 & 11 & - & - & - & - & - & - & - & - \\
\hline May & 11 & 9 & 20 & - & - & - & - & - & - & - & - \\
\hline Jun & 27 & 31 & 58 & 4 & 6.89 & 1 & 1.72 & - & - & 1 & 1.72 \\
\hline Jul & 67 & 35 & 127 & 44 & 34.44 & - & - & 1 & 1.72 & - & - \\
\hline Aug & 27 & 41 & 68 & 22 & 32.35 & - & - & - & - & - & - \\
\hline Sep & 22 & 28 & 50 & 16 & 32 & - & - & - & - & - & - \\
\hline Total & 263 & 186 & 349 & 88 & 25.21 & 1 & 0.28 & 1 & 0.28 & 1 & 0.28 \\
\hline
\end{tabular}

Table 2. Age and Gender wise Distribution of Patients.

\begin{tabular}{|c|c|c|c|c|c|}
\hline Age(years) & Total numbers of patients & Infected Female & Infected Male & Total infected & $\%$ of infected \\
\hline $0-5$ & 20 & 1 & - & 1 & 1.09 \\
\hline $6-15$ & 34 & 5 & 2 & 7 & 7.7 \\
\hline $16-30$ & 150 & 28 & 25 & 53 & 58.24 \\
\hline $31-45$ & 70 & 4 & 13 & 17 & 16.68 \\
\hline$>46$ & 75 & 3 & 10 & 13 & 14.28 \\
\hline Total & 349 & 41 & 50 & 91 & 26.07 \\
\hline
\end{tabular}

\begin{tabular}{|lccc|}
\hline Table 3. Number of patients Vs Educational status \\
\hline $\begin{array}{l}\text { Educational } \\
\text { Status }\end{array}$ & $\begin{array}{c}\text { Total numbers } \\
\text { of patients }\end{array}$ & $\begin{array}{c}\text { Total number } \\
\text { of Positive } \\
\text { cases }\end{array}$ & Total \% \\
Educated & 30 & 9 & 9.89 \\
Literate & 188 & 30 & 32.97 \\
Illiterate & 131 & 5 & 57.14 \\
Total & 349 & 91 & 26.07 \\
\hline \hline
\end{tabular}

test (Table 5). Among the antibiotics used Ciprofloxacin $(97.84 \%)$ was found to be most sensitive antibiotic followed by Norfloxacin (93.41\%), Tetracycline (92.34\%) and Erythromycin (92.34\%) respectively.

\section{DISCUSSION}

In a developing country like Nepal, diarrhoeal disease is a major cause of morbidity and mortality. It is difficult to distinguish on clinical grounds similar infections caused by the different pathogens as most of these pathogens have similar clinical features. A precise diagnosis can only be achieved by laboratory means, which is important epidemiological investigation and control means. ${ }^{4}$

Despite the global recognition of severe ill effects of the disease and the enormous amount of resources being

\begin{tabular}{|lccc|}
\hline Table 4. Number of patients Vs Sanitary Condition. \\
\hline Hygiene & $\begin{array}{c}\text { Total no. of } \\
\text { Person }\end{array}$ & $\begin{array}{c}\text { Total no. of } \\
\text { Positive cases }\end{array}$ & $\%$ \\
Good & 30 & 10 & 10.8 \\
Intermediate & 109 & 20 & 21.97 \\
Poor & 210 & 61 & 67.03 \\
Total & 349 & 91 & 26.07 \\
\hline \hline
\end{tabular}

spent to control their spread, diarrhoea still remains endemic in many countries for a number of reasons. Ramshackle housing, lack of piped water and sanitation, widespread faecal contamination of the environment, lack of personal hygiene, high incidence of malnutrition and infection, overcrowding of children under five years of age in one house have been found to be the contributing factors. Enteric infections particularly due to bacterial pathogens are readily transmitted under these circumstances. ${ }^{5}$

Thus diarrhoeal diseases are priority health problems in all developing countries. Diarrhoeal and other intestinal infections have high morbidity and mortality in Nepalese children. This study found 91 cases caused by pathogenic microorganisms. Among these, $25.5 \%$ of the total cases were due to Vibrio cholerae $01,0.28 \%, 0.28 \%$ and 


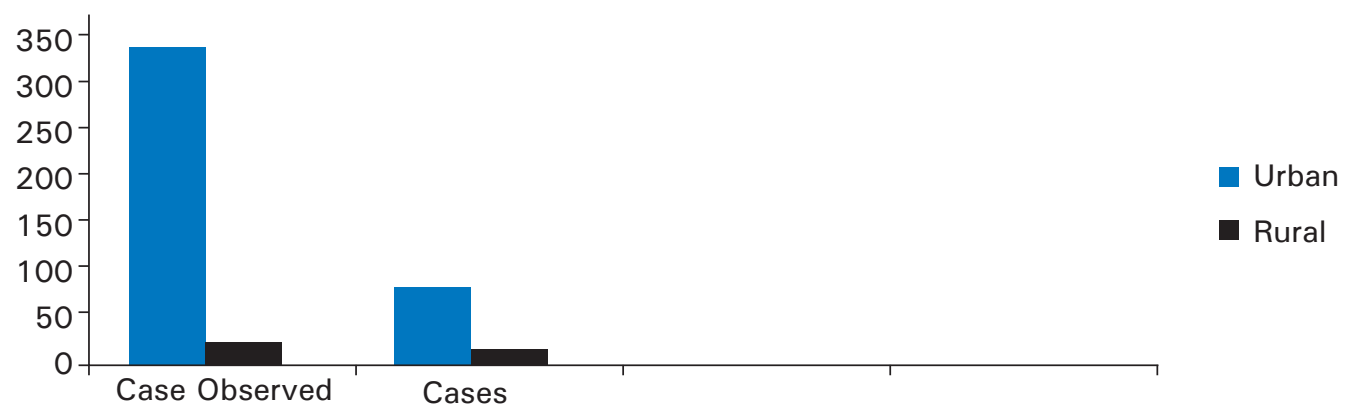

Figure 1. Area Distribution of the total cases.

$0.28 \%$ were found to be due to Vibrio cholerae 0139, Shigella dysenteriae and Escherichia coli respectively. The picture is similar to a study in Northern Jordan where one or more bacterial as well as parasitic enteropathogen was isolated from 79 cases $(40 \%)$ of the total 200 diarrhoea patients. ${ }^{6}$

Among these cholera was seen through out the year in the country though the number increased during the rainy season with highest infection in July (34.6\%) followed by June, August and September. In this study it was found that people with poor hygiene and lack of education were infected more than other communities. Most of the bacteria in this study were found to be sensitive to antibiotics however the problem of resistant bacteria cannot be overlooked.

In Riyad, 54 Escherichia coli strains from faeces were resistant to four to six commonly used antibiotics such as Tetracycline, Ampicillin, Chloramphenicol, Kanamycin, Streptomycin and Co-trimoxazole. ${ }^{7}$ Most of the Shigella strains were resistant simultaneously to Chloramphenicol, Ampicillin, Streptomycin, Tetracycline, Neomycin and
Kanamycin. ${ }^{8}$ IA study by Thapa et $\mathrm{al}^{9}$ found that most Shigella species were sensitive towards Neomycin, Furazolodian and Cephoridine, where as they were resistant to Tetracycline, Ampicillin, Chloramphenicol and Co-trimoxazole.

Diarrhoeal disease in older people is caused by Shigella (M.60) i.e. $0.28 \%$ due to food contamination. Shigella infection, which causes acute diarrhoea is also transmitted by organofaecal route where a small number of organism is sufficient to cause the disease. The frequency of the disease was greater at the age of 14 years. ${ }^{10}$

In this country, fatality rate from diarrhoea is highest $(74.7 \%)$ in the age group of $16-30$ years and is lowest $(1.09 \%)$ in $0-5$ years. It may be due to good practice in breast feeding and good management at home. Hard labor, lack of education and unhygienic condition with bad sanitation and untreated water supply are important causes of these outbreaks.

Out of 349 diarrhoea patients, $54.84 \%$ were male and $45.05 \%$ were female. Hulian ${ }^{11}$ also reported higher

Table 5. Antibiotic Sensitivity pattern of bacteria isolated as whole

\begin{tabular}{|c|c|c|c|c|c|c|c|c|}
\hline Antibiotics & Disc Potency & $\mathbf{R}$ & $\mathbf{R}^{*}$ & $\mathbf{S}$ & $\mathbf{S}^{*}$ & I & $I^{*}$ & $\begin{array}{c}\text { Zone diameter limits } \\
\text { for Vibrio cholerae } \\
\text { (mm) }\end{array}$ \\
\hline Tetracycline & 30 & 7 & 7.69 & 84 & 92.34 & - & - & $24-29$ \\
\hline Ciprofloxacin & 5 & 2 & 2.1 & 89 & 97.84 & - & - & $24-27$ \\
\hline Erythromycin & 15 & 2 & 2.1 & 84 & 92.34 & 5 & 5.49 & $15-25$ \\
\hline Chloramphenicol & 30 & 91 & 100 & - & - & - & - & 0 \\
\hline Ampicillin & 10 & 91 & 100 & - & - & - & - & $0-6$ \\
\hline Norfloxacin & 10 & 6 & 6.59 & 85 & 93.41 & - & - & $20-25$ \\
\hline Cotrimoxazole & 10 & 91 & 102 & - & - & - & - & 0 \\
\hline
\end{tabular}

*in percent, S-Sensitive, R-Resistant, I-Intermediate 
number of male patients as compared to female patients to have suffered from diarrhoea (60\%).A study of 1992 1993 did not show any sex variations among the diarrhoeal patients in China. The mortality rate among children below two years suffering from diarrhoea was shown to be 15 times more than the children above two years of age.

\section{CONCLUSION}

During the period January to September 1997, total of 349 patients of all ages suffering from diarrhoea were studied. In this case $25.1 \%, 0.28 \%, 0.28 \%, 0.28 \%$ were found to be Vibrio cholera 01, Vibrio cholerae 0139, Shigella dysenteriae and Escherichia coli respectively. Total isolation rate of Vibrio cholerae was $25.5 \%$ among the diarrhogenic cases.

\section{REFERENCES}

1. World Health Organization. Manual for the Laboratory Investigations of Acute Enteric Infections. Geneva: World Health Organization; 1993 Publication No. WHO/CDD/83.3 REV.1.

2. Center for Disease Control. CDC, Update: Cholera - Western Hemisphere, 1992 mmwr 1993;42:89-91.

3. Keush GT, Bennish ML. Bacterial infection of Humans: epidemiology and control: Shigellosis. 2nd ed. Newyork: Plenum; 1991. p.593.

4. College JG, Duguid JP, Fraser AG, Marmion BP. Mackie and Mac Cartney, Practical Medical Microbiology. vol. 2. 13th ed. Churchill Livingstone; 1989.

5. Levine MM, Levine OS. Changes in human ecology and behaviour in relation to the emergence of diarrhoeal diseases, including cholera. Proceedings of the National Academy of Sciences of the United States of America; 1994:91(7):2390-94.

6. Na'swas TE, Mahmoud NA. A study of the bacterial and parasitic cause of acute diarhoea in Northern Jordan. J. Diarrh.
Dis. Res 1991;9(4):305-309.

7. Hug ML, Swailen AR, Fares S, Alim AR. Studies on the etiological agents of infantile diarrhoea in Riyad. Ind. Paed. 1988;52:293-319.

8. Shishkina ZU, Malyugina AP, Shubin LL. Antibiotic sensitivity of 104 Shigella clinical strains and 104 Esch. coli strains isolated from patients with acute dysentery not treated with antibiotics in 1986-87. Antibiot. Khimioter 1989;34(10):749-50.

9. Thapa BR, Ventkateswarlu K, Malik AK, Panifrahi. Shigellosis in children from N. India: A clinicopathological study. J. trop Paed 1995;41(5):030-7.

10. Kouppari GZ, Tsierpam A et al. Clinical laboratory study of Shigella spp enteritis in children. Deltion Ellenikes Microbial Etareias 1995;49(4):309-17.

11. Hulin S, Zhen LG, Mathan MM et al. Etiology of acute diarrhea among children in developing countries: A multicenter study in five countries, Bull, WHO 1991;69(5):549-55. 